\title{
Analisis Ketersediaan dan Kebutuhan Ruang Terbuka Hijau Publik pada Kawasan Perkotaan Bintuni di Wilayah Distrik Manimeri
}

\author{
Jendro Edy Wibowo'; Wahyudi'; Rima H S Siburian ${ }^{1}$ \\ Universitas Papua, Manokwari 98314 \\ ${ }^{1}$ r.siburian@unipa.ac.id
}

\begin{abstract}
Abstrak
Meskipun merupakan daerah otonomi baru, ketersediaan ruang terbuka hijau di pusat pemerintahan Teluk Bintuni memenuhi kriteria Peraturan Menteri Pekerjaan Umum No. 05 tahun 2008. Penelitian ini bertujuan untuk menganalisis ketersedian ruang terbuka hijau saat ini dan menperkirakan kebutuhan untuk sepuluh tahun kedepan dengan pendekatan jumlah penduduk. Metode survey lapangan, pemetaan menggunakan Citra Satelit Resolusi Sangat Tinggi dan Citra lansat serta softawar GIS digunakan untuk menganalisis data digital. Hasil penelitian menunjukkan bahwa ketersediaan ruang terbuka hijau publik pada kawasan perkotaan di wilayah Distrik Manimeri terdiri dari hutan kota (22,12 ha) sudah terpenuhi, jalur hijau jalan (17,94 ha), lapangan olahraga (4,56 ha), median jalan (0,914 ha), sempadan sungai (155,15 ha), taman kelurahan $(0,21$ ha) dan taman pemakaman umum (1,77 ha). Kebutuhan ruang terbuka hijau publik berdasarkan pendekatan jumlah penduduk sepuluh tanun kedepan bagi Taman rukun tetangga 0,95 ha, Taman rukun warga 0,48 ha, Taman kelurahan/kampung 0,29 Ha. Taman kecamatan/distrik 0,1902 ha dan Taman kota 0,2853 ha. Pemenuhan kriteria RTH publik berdasarlan Permen PU No 05 Tahun 2008, untuk jenis RTH hutan kota secara umum terpenuhi, jenis RTH jalur hijau jalan seluruhnya terpenuhi, jenis RTH median jalan secara umum tidak terpenuhi, jenis RTH sempadan sungai seluruhnya terpenuhi, jenis RTH taman kelurahan secara umum tidak terpenuhi dan jenis RTH taman pemakaman umum secara umum tidak terpenuhi.
\end{abstract}

Kata kunci: Ketersediaan, Kebutuhan, Kriteria, Ruang Terbuka Hijau, Distrik Manimeri.

\section{PENDAHULUAN}

Kabupaten Teluk Bintuni merupakan salah satu kabupaten yang dibentuk berdasarkan Undang-undang Nomor 26 tahun 2002 dengan luas daratannya 18.637 km². Berdasarkan Undang-undang Nomor 26 Tahun 2007 pasal 29 ayat 2 tentang Penataan Ruang, setiap wilayah kota harus menyediakan Ruang Terbuka Hijau (RTH) sebesar 30 persen dari luas wilayah dengan proporsi 20 persen RTH publik dan 10 persen RTH Privat.

Kebutuhan akan RTH pada suatu wilayah dapat ditentukan antara lain melalui indikator jumlah penduduk. Perkembangan Kawasan Perkotaan Bintuni sebagai pusat dari Wilayah Pengembangan (WP) Bintuni yang diatur dalam Rencana Tata Ruang Wilayah Kabupaten Teluk Bintuni Tahun 2012 - 2032, telah menunjukkan bahwa pada 20 tahun kedepan diprediksikan memiliki perkembangan yang signifikan. Kawasan 


\section{Median Volume 12 Nomor 3 Bulan Oktober 2020}

Perkotaan Bintuni berada pada wilayah Distrik Bintuni dan wilayah Distrik Manimeri, kawasan pada Wilayah Distrik Manimeri lebih diarahkan pada pengembangan pusat pemerintahan baik vertikal maupun otonom.

Kawasan Perkotaan yang berada di wilayah Distrik Manimeri sekalipun di arahkan sebagai pusat pemerintahan namun perkembangannya dapat mengakibatkan terjadinya perubahan kondisi ekologis lingkungan perkotaan yang menyebabkan penurunan kualitas lingkungan (Arief et al 2019) sehingga keberadaan Ruang Terbuka Hijau (RTH) sangat diperlukan guna menjaga kualitas lingkungan. Seiring dengan peningkatan pembangunan dan meningkatnya jumlah penduduk, maka perlu adanya analisis ketersedian dan kebutuhan Ruang Terbuka Hijau (RTH) publik pada kawasan perkotaan yang berada di wilayah Distrik Manimeri, dengan pendekatan indikator peningkatan jumlah penduduk.

\section{METODE PENELITIAN}

Penelitian ini berlokasi di wilayah pusat perkotaan Bintuni, tepatnya di Distrik Manimeri, meliputi enam kampung yaitu Kampung Atibo, Banjar Ausoy, Bumi Saniari, Korano Jaya, Pasamai, dan Waraitama. Penelitian berlangsung selama satu minggu, yaitu 26 September - 2 Oktober 2020.

Objek yang diteliti meliputi RTH pada kawasan perkotaan di wilayah Distrik Manimeri. Metode penelitian menggunakan metode observasi lapang dimana data diperoleh secara langsung dengan menghitung ketersedian RTH Publik pada kawasan perkotan selanjutnya akan dikembangkan secara kuantitatif dalam menganalisa kebutuhan luasan RTH berdasarkan peningkatan jumlah penduduk. Analisa kebutuhan Ruang Terbuka Hijau akan dilakukan untuk 10 (sepuluh) tahun kedepan. Variabel dalam penelitian ini meliputi variabel utama yaitu letak dan luas ruang terbuka hijau (RTH) publik, penggunaan lahan, identifikasi pemenuhan kriteria. Variabel penunjang meliputi data jumlah penduduk. Pengumpulan data primer dilakukan dengan mengidenfikasi keberadaan ruang terbuka hijau serta memetakan dengan metode digitation on screen berbahan Citra Satelit Resolusi Sangat Tinggi, sedangkan indentifikasi RTH dilakukan meliputi bentuk, luas, lokasi, persentase luas tanaman hijau, jumlah pohon pelindung, fasilitas yang ada, jumlah penduduk yang dilayani dan keberadaan pohon pelindung, struktur hutan dan lebar RTH (untuk sempadan sungai). Untuk pemakaman meliputi ukuran makam, jarak antar makam, penembokan makam, pembagian blok makam, batas antar blok, batas terluar pemakanan, persentase liputan vegetasi dan persentasi RTH. Identifikasi dilakukan untuk mengetahui karakteristik ruang terbuka hijau.

Data sekunder berupa jumlah penduduk per RT, RW dan kampung diperoleh dari pemerintah kampung Atibo, kampung Banjar Ausoy, kampung Bumi Saniari, Kampung Korano Jaya, kampung Pasamai dan kampung Waraitama sedangkan laju pertumbuhan penduduk diperoleh dari Badan Pusat Statistik Kabupaten Teluk Bintuni. Peta yang 


\section{Median Volume 12 Nomor 3 Bulan Oktober 2020}

Doi http://doi.org/md.v12i3.731

diperoleh digunakan untuk memperhitungkan luas ketersediaan RTH sedangkan hasil identifikasi RTH digunakan untuk mendiskripsikan ruang terbuka hijau. Pemperhitungan kebutuhan ruang terbuka hijau berdasarkan jumlah penduduk diperhitungkan melalui aplikasi matematis menggunakan rumus geometri proyeksi jumlah penduduk sebagai berikut :

$\mathrm{Pt}=\mathrm{Po}(1+\mathrm{r}) \mathrm{t}$ dimana $\mathrm{r}=\operatorname{antilog}(1 / \mathrm{t})(\log (\mathrm{Pt} / \mathrm{Po})-1)$

Dimana : $\mathrm{Pt}=$ jumlah penduduk akhir (tahun proyeksi),

Po = jumlah penduduk tahun dasar

$\mathrm{r}$ = laju pertumbuhan penduduk (\%),

$\mathrm{t}$ = waktu (tahun).

Sedangkan : KRTH $=$ LRTH $\times$ Jumlah penduduk $($ Jiwa $)$,

Dimana: $\quad \mathrm{KRTH}=$ kebutuhan

RTHL RTH = luas RTH.

Analisis data ditampilkan secara tabulasi yang kemudian dideskripsikan

\section{HASIL DAN PEMBAHASAN}

\section{Ketersediaan Ruang Terbuka Hijau}

Hasil Pengolahan data Citra Satelit Resolusi Sangat Tinggi untuk mengetahui ketersediaan ruang terbuka hijau wilayah perkotaan Bintuni di Distrik Manimeri berdasarkan Permen PU No.05 Tahun 2008 disajikan pada Tabel 1.

Tabel 1. Ketersediaan ruang terbuka hijau wilayah perkotaan Bintuni di distrik Manimeri

\begin{tabular}{|c|c|c|c|c|c|c|}
\hline \multirow{20}{*}{$\begin{array}{c}\text { Jenis } \\
\text { Ruang } \\
\text { Terbuka } \\
\text { Hijau } \\
\text { (RTH) }\end{array}$} & Private & $\begin{array}{l}\text { Luas } \\
\text { (ha) }\end{array}$ & Publik & $\begin{array}{l}\text { Luas } \\
\text { (ha) }\end{array}$ & Non-RTH & $\begin{array}{l}\text { Luas } \\
\text { (ha) }\end{array}$ \\
\hline & Taman & 34,04 & Hutan Kota & 22,12 & Area Terbuka & 188,73 \\
\hline & Lingkungan & & Jalur Hijau Jalan & 17,94 & Bangunan Transportasi & 0,08 \\
\hline & Perkantoran & & Lapangan Olahraga & 4,56 & $\begin{array}{l}\text { Hutan Lahan Kering } \\
\text { sekunder }\end{array}$ & $5.527,23$ \\
\hline & & & Median Jalan & 0,91 & Jalan & 44,52 \\
\hline & & & Sempadan Sungai & 155,15 & Kesehatan & 0,11 \\
\hline & & & Taman Kelurahan & 0,21 & Kolam & 0,10 \\
\hline & & & Taman Pemakaman Umum & 1,77 & Pekarangan & 5,01 \\
\hline & & & & & Pendidikan & 1,73 \\
\hline & & & & & Peribadatan & 0,57 \\
\hline & & & & & Perkantoran dan & 4,26 \\
\hline & & & & & Perekonomian & \\
\hline & & & & & Perkebunan & 303,62 \\
\hline & & & & & Permukiman & 27,56 \\
\hline & & & & & Pertahanan dan Keamanan & 0,68 \\
\hline & & & & & Rawa & 4,01 \\
\hline & & & & & Sawah & 395,85 \\
\hline & & & & & Semak Belukar & 347,91 \\
\hline & & & & & Sungai & 270,06 \\
\hline & & & & & Tambak & 2,54 \\
\hline \multicolumn{2}{|c|}{ Total (ha) } & 34,04 & & 202,66 & & $7,124,53$ \\
\hline \multicolumn{2}{|c|}{ Persentase (\%) } & 0,46 & & 2,75 & & 96,79 \\
\hline
\end{tabular}




\section{Median Volume 12 Nomor 3 Bulan Oktober 2020}

Doi http://doi.org/md.v12i3.731

Tabel 1 menjelaskan bahwa mayoritas tutupan lahan $(96,79 \%)$ di wilayah perkotaan Bintuni distrik Manimeri adalah non-RTH, dimana didominasi oleh hutan lahan kering (5.527,23 ha), Sawah (395, 85 ha) dan semak belukar (347,91 ha). Sedangkan RTH public didomomiasi oleh sempadan sungai $(155,15$ ha) atau sebesar 76,56 \%. Wilayah Teluk Bintuni lebih didominasi oleh ekosistem rawa dan mangrove, sehingga sempadan sungai lebih dominan, seperti ditunjukkan oleh Gambar 1.

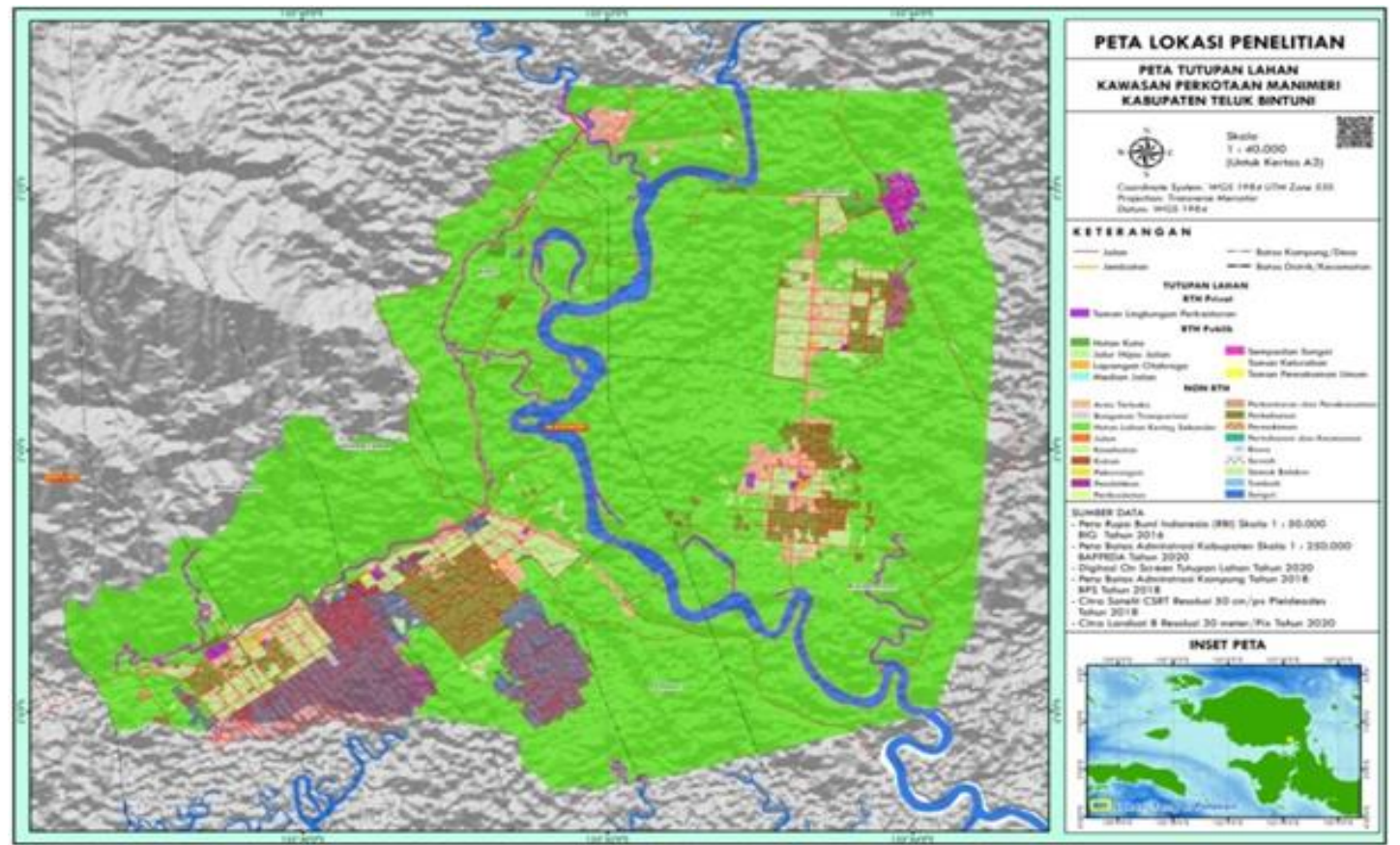

Gambar 1. Sebaran tutupan lahan kawasan perkotaan Manimeri Kabupaten Teluk Bintuni

Rincian luas RTH publik yang tersebar pada enam kampung di Distrik Manimeri dapat dilihat pada Gambar 2.

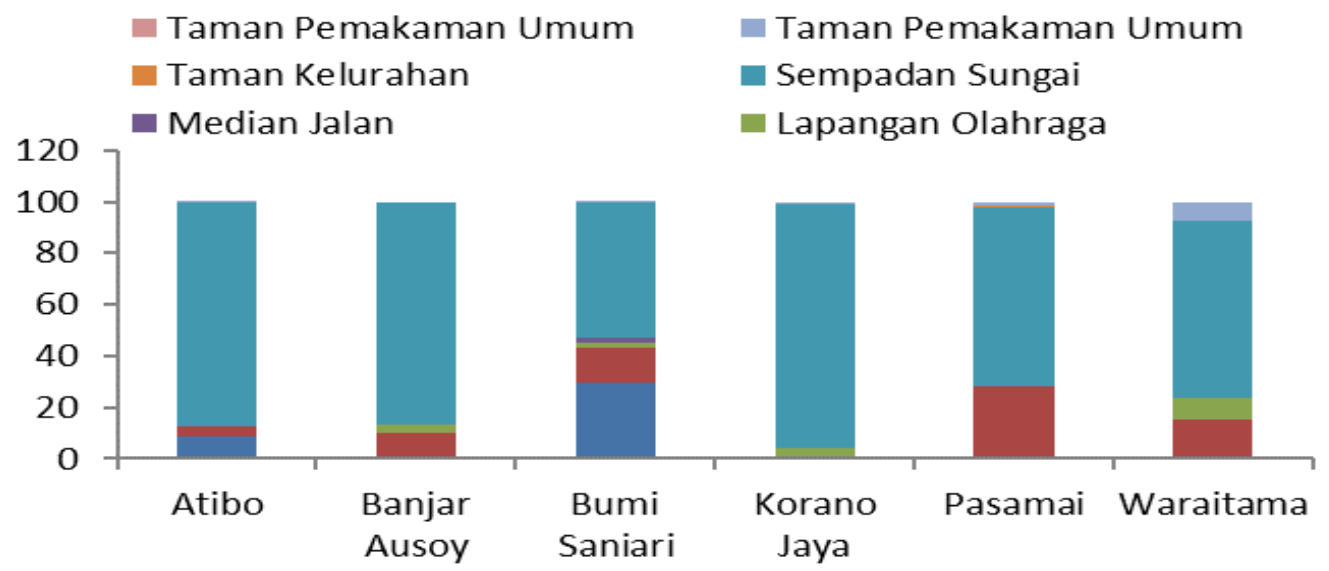

Gambar 2. Sebaran RTH Publik pada enam kampung di Distrik Manimeri 


\section{Median Volume 12 Nomor 3 Bulan Oktober 2020}

Doi http://doi.org/md.v12i3.731

\section{Taman Kampung}

Tabel 2. Kesesuaian ruang terbuka hijau taman kampung/kelurahan pada wilayah perkotaan Bintuni di Distrik Manimeri

\begin{tabular}{|c|c|c|c|c|c|c|}
\hline \multirow[t]{2}{*}{ Bentuk } & \multicolumn{2}{|c|}{$\begin{array}{c}\text { Arahan } \\
\text { Permen PU }\end{array}$} & \multicolumn{2}{|c|}{ Kondisi existing } & \multicolumn{2}{|c|}{$\begin{array}{c}\text { Kesesuaian eksisting } \\
\text { dengan Permen PU } \\
(\text { Pemenuhan kriteria })^{*, \#}\end{array}$} \\
\hline & $\begin{array}{c}\text { Bumi } \\
\text { Saniari }\end{array}$ & Pasamai & $\begin{array}{c}\text { Bumi } \\
\text { Saniari }\end{array}$ & Pasamai & $\begin{array}{c}\text { Bumi } \\
\text { Saniari }\end{array}$ & Pasamai \\
\hline Bentuk & Taman & Taman & Belukar & Taman & $\begin{array}{l}\text { Tidak } \\
\text { sesuai }^{\#}\end{array}$ & Sesuai* \\
\hline Luas & 0.0436 ha & 0.0041 ha & 0,166 ha & 0,060 ha & Sesuai* & Sesuai* \\
\hline Lokasi & Kelurahan & Kelurahan & Kelurahan & kelurahan & Sesuai* & Sesuai* \\
\hline Luas Tanaman & $80-90 \%$ dari & $80-90 \%$ & $0 \%$ & $0 \%$ & Tidak & Tidak \\
\hline Hijau & luas taman & $\begin{array}{l}\text { dari luas } \\
\text { taman }\end{array}$ & & & sesuai $^{\#}$ & sesuai $^{\#}$ \\
\hline $\begin{array}{l}\text { Keberadaan } \\
\text { pohon } \\
\text { pelindung }\end{array}$ & 50 pohon & 50 pohon & 0 Pohon & 0 Pohon & $\begin{array}{l}\text { Tidak } \\
\text { sesuai }^{\#}\end{array}$ & $\begin{array}{l}\text { Tidak } \\
\text { sesuai }^{\#}\end{array}$ \\
\hline
\end{tabular}

\section{Hutan Kota}

Tabel 3. Kesesuaian ruang terbuka hijau hutan kota pada wilayah perkotaan Bintuni di Distrik Manimeri

\begin{tabular}{cllcc}
\hline No & \multicolumn{1}{c}{ Permen PU } & $\begin{array}{c}\text { BentukBergerombol } \\
\text { Jumlah Vegetasi minimal 100 } \\
\text { pohon, tidak beraturan }\end{array}$ & $\begin{array}{c}\text { RTH } \\
\text { Minimal 90-100\% } \\
\text { dari luas hutan kota }\end{array}$ & $\begin{array}{c}\text { Strutur hutan Kota } \\
\text { Berstrata dua atau } \\
\text { banyak }\end{array}$ \\
\hline 1 & Hutan Kota Rimbawan & Jumlah pohon $>100$ pohon * & $100 \% *$ & berstrata banyak $*$ \\
2 & Hutan kota Buni Saniari & jumlah pohon $>100$ pohon $*$ & $90 \% *$ & berstrata banyak $*$ \\
3 & Hutan Kota Muturi I & jumlah pohon $>100$ pohon $*$ & $100 \% *$ & berstrata banyak $*$ \\
4 & Hutan Kota Muturi II & jumlah pohon $>100$ pohon $*$ & $100 \% *$ & berstrata banyak $*$ \\
5 & Hutan Kota Rajawali & jumlah pohon $<100$ pohon & $100 \% *$ & berstrata satu \\
6 & Hutan Kota Manimeri & jumlah pohon $>100$ pohon $*$ & $100 \% *$ & berstrata banyak $*$ \\
\hline \multicolumn{7}{l}{ Keterangan: * terpenuhi, \# tidak terpenuhi }
\end{tabular}

\section{Pulau dan Median Jalan}

RTH jenis pulau dan median jalan di wilayah Manimeri cukup tersedia, tetapi tidak sesuai dan memenuhi kriteria

Tabel 4. Kesesuaian ruang terbuka hijau Pulau dan median jalan wilayah perkotaan Bintuni di Distrik Manimeri

\begin{tabular}{|c|c|c|c|c|c|c|}
\hline \multirow{2}{*}{$\begin{array}{c}\text { Arahan permen PU No } 5 \\
2008\end{array}$} & $\begin{array}{c}\text { Jenis } \\
\text { Tanaman }\end{array}$ & $\begin{array}{c}\text { Jarak } \\
\text { tanam }\end{array}$ & $\begin{array}{c}\text { Ketinggian } \\
\text { tanaman }\end{array}$ & Massa daun & \multirow[t]{2}{*}{ Kesuaian } & \multirow{2}{*}{$\begin{array}{l}\text { Pemenuhan } \\
\text { criteria }\end{array}$} \\
\hline & perdu/semak & rapat & $1.5 \mathrm{~m}$ & daun padat & & \\
\hline Median jalan perkantoran & $\begin{array}{l}\text { Pohon dan } \\
\text { perdu }\end{array}$ & rapat & Tinggi $7 \mathrm{~m}$ & $\begin{array}{l}\text { daun tidak } \\
\text { padat }\end{array}$ & $\begin{array}{l}\text { Tidak } \\
\text { sesuai }\end{array}$ & $\begin{array}{c}\text { Tidak } \\
\text { terpenuhi }\end{array}$ \\
\hline $\begin{array}{l}\text { Median Jalan poros Bumi } \\
\text { Saniari }\end{array}$ & Jenis palem & jarang & Tinggi $1 \mathrm{~m}$ & $\begin{array}{l}\text { Daun tidak } \\
\text { padat }\end{array}$ & $\begin{array}{l}\text { Tidak } \\
\text { sesuai }\end{array}$ & $\begin{array}{l}\text { Tidak } \\
\text { terpenuhi }\end{array}$ \\
\hline
\end{tabular}




\section{Median Volume 12 Nomor 3 Bulan Oktober 2020}

Doi http://doi.org/md.v12i3.731

\section{RTH Pemakaman}

Tabel 5. Kesesuaian ruang terbuka hijau pemakaman pada wilayah perkotaan Bintuni di distrik Manimeri

\begin{tabular}{|c|c|c|c|c|c|c|c|}
\hline \multirow[b]{2}{*}{$\begin{array}{l}\text { Permen PU no } \\
52008\end{array}$} & \multicolumn{3}{|c|}{ Makam } & \multicolumn{2}{|c|}{ Blok } & \multirow{2}{*}{$\begin{array}{c}\text { Batas luar } \\
\text { Pagar } \\
\text { tanaman } \\
\text { atau } \\
\text { buatan }\end{array}$} & \multirow{2}{*}{$\begin{array}{c}\text { RTH } \\
\text { Minimal } \\
70 \% \\
\text { dengan } \\
80 \% \text { luas }\end{array}$} \\
\hline & $\begin{array}{l}\text { Ukuran } \\
\text { (m) } \\
1 \times 2\end{array}$ & $\begin{array}{c}\text { Jarak } \\
(\mathrm{m}) \\
0.5\end{array}$ & $\begin{array}{c}\text { Tidak } \\
\text { boleh } \\
\text { ditembok }\end{array}$ & $\begin{array}{l}\text { Dibagi } \\
\text { kedalam } \\
\text { blok }\end{array}$ & $\begin{array}{c}1,5-2 \mathrm{~m} \\
\text { pedestrian } \\
\text { dengan pohon } \\
\text { pelindung }\end{array}$ & & \\
\hline Pemakaman & & & & & & & \\
\hline Atibo & $1 \times 2 \mathrm{~m}$ & 0.5 & ditembok & $\begin{array}{l}\text { Tidak } \\
\text { terbagi } \\
\text { blok }\end{array}$ & $\begin{array}{l}\text { Tidak ada } \\
\text { batas }\end{array}$ & Tidak ada & $\begin{array}{c}34,17 \% \\
\text { dan } 65,88\end{array}$ \\
\hline Kesesuaian & S & S & $\mathrm{TS}$ & TS & TS & TS & TS \\
\hline Keterpenuhan & $\mathrm{T}$ & $\mathrm{T}$ & TP & $\mathrm{TP}$ & TP & $\mathrm{TP}$ & $\mathrm{TP}$ \\
\hline Bumi Saniari & $1 \times 2 \mathrm{~m}$ & 0,5 & Ditembok & $\begin{array}{l}\text { Tidak } \\
\text { terbagi } \\
\text { blok }\end{array}$ & $\begin{array}{c}\text { Tdak ada } \\
\text { batas }\end{array}$ & Tidak ada & $\begin{array}{c}19,07 \% \\
\text { dan } \\
80,93 \%\end{array}$ \\
\hline Kesesuaian & S & S & $\mathrm{TS}$ & $\mathrm{TS}$ & $\mathrm{TS}$ & $\mathrm{TS}$ & $\mathrm{TS}$ \\
\hline Keterpenuhan & $\mathrm{T}$ & $\mathrm{T}$ & $\mathrm{TP}$ & $\mathrm{TP}$ & $\mathrm{TP}$ & $\mathrm{TP}$ & $\mathrm{TP}$ \\
\hline Korano Jaya & $1 \times 2 \mathrm{~m}$ & 0,5 & Ditembok & $\begin{array}{l}\text { Tidak } \\
\text { terbagi } \\
\text { blok }\end{array}$ & $\begin{array}{c}\text { Tdak ada } \\
\text { batas }\end{array}$ & Tidak ada & $\begin{array}{l}19,04 \% \\
\text { dan } \\
80,96 \%\end{array}$ \\
\hline Kesesuaian & S & S & $\mathrm{TS}$ & TS & $\mathrm{TS}$ & $\mathrm{TS}$ & TS \\
\hline Keterpenuhan & $\mathrm{T}$ & $\mathrm{T}$ & $\mathrm{TP}$ & $\mathrm{TP}$ & $\mathrm{TP}$ & $\mathrm{TP}$ & $\mathrm{TP}$ \\
\hline Pasamai & $1 \times 2 \mathrm{~m}$ & 0,5 & Ditembok & $\begin{array}{l}\text { Tidak } \\
\text { terbagi } \\
\text { blok }\end{array}$ & $\begin{array}{c}\text { Tdak ada } \\
\text { batas }\end{array}$ & Tidak ada & $\begin{array}{c}26,56 \% \\
\text { dan } \\
73,44 \%\end{array}$ \\
\hline Kesesuaian & S & S & $\mathrm{TS}$ & $\mathrm{TS}$ & TS & TS & TS \\
\hline Keterpenuhan & $\mathrm{T}$ & $\mathrm{T}$ & TP & $\mathrm{TP}$ & $\mathrm{TP}$ & $\mathrm{TP}$ & TP \\
\hline Waraitama & $1 \mathrm{x} 2 \mathrm{~m}$ & 0,5 & Ditembok & $\begin{array}{l}\text { Tidak } \\
\text { terbagi } \\
\text { blok }\end{array}$ & $\begin{array}{c}\text { Tdak ada } \\
\text { batas }\end{array}$ & Tidak ada & $\begin{array}{c}4,19 \% \text { dan } \\
95,81 \%\end{array}$ \\
\hline Kesesuaian & S & S & $\mathrm{TS}$ & TS & TS & TS & $\mathrm{TS}$ \\
\hline Keterpenuhan & $\mathrm{T}$ & $\mathrm{T}$ & $\mathrm{TP}$ & $\mathrm{TP}$ & $\mathrm{TP}$ & TP & TP \\
\hline
\end{tabular}

Keterngan $: S=$ Sesuai, $T=$ Terpenuhi, $T S=$ Tidak sesuai, $T P=$ Tidak terpenuhi

Hasil penelitian menunjukkan bahwa terdapat Taman Kelurahan/Kampung seluas 0,21 Ha yang terletak pada Kampung Bumi Saniari selaus 0,15 Ha dan Kampung Pasamai seluas 0,06 Ha.Taman Kelurahan/Kampung di Bumi Saniari bila dibandingkan dengan luas minimum yang didasarkan pada jumlah penduduk sudah memenuhi luas RTH yang diwajibkan bahkan memenuhi kebutuhan luas RTH untuk 10 tahun kedepan. Taman Kelurahan/Kampung di Pasamai bila dibandingkan dengan luas minimum yang didasarkan pada jumlah penduduk saat ini sudah memenuhi luas RTH yang diwajibkan bahkan untuk 10 tahun kedepan.Untuk kampung-kampung lainnya guna memenuhi taman kelurahan/kampung saat ini, kampung Atibo, harus menyediakan 0,0087 Ha, kampung Banjar Ausoy harus menyediakan seluas 0,0938 Ha, kampung Korano Jaya harus menyediakan 0,0340 Ha dan kampung Waraitama harus menyediakan seluas $0,0455 \mathrm{Ha}$. 


\section{Median Volume 12 Nomor 3 Bulan Oktober 2020}

Doi http://doi.org/md.v12i3.731

Untuk memenuhi kebutuhan taman kelurahan/kampung 10 tahun kedepan adalah maka kampung Atibo harus menyediakan seluas 0,0109 Ha kampung Banjar Ausoy menyediakan seluas 0,1156 Ha, kampung Korano Jaya menyediakan seluas 0,0425 Ha, dan kampung Waraitama menyediakan seluas 0,0571 Ha.Ketersediaan Taman RT dan Taman RW tidak terdapat di semua RT dan RW.

\section{KESIMPULAN}

RTH publik pada kawasan perkotaan di wilayah distrik Manimeri terdiri dari hutan kota, jalur hijau jalan, lapangan olahraga, median jalan, sempadan sungai, taman kelurahan dan taman pemakaman umum. Secara umum keberadaan RTH Publik memenuhi kriteria Permen PU No 05 Tahun 2008. Kebutuhan RTH publik yang didasarkan variabel pertumbuhan penduduk untuk 10 tahun kedepan Taman RT 0,951 Ha, Taman RW 0,4755 Ha, Taman kelurahan/kampung 0,2853 Ha, Taman kecamatan/distrik 0,1902 Ha dan Taman kota 0,2853 Ha.

\section{DAFTAR PUSTAKA}

Arief S, Siburian R H, Wahyudi. 2019. Tingkat Kerentanan Banjir Kota Sorong Papua Barat. Median Volume 11 Nomor 2 Bulan Juni 2019. pp 23-27.

Badan Pusat Statistik, 2018. Kabupaten Teluk Bintuni dalam Angka 2018.

Badan Pusat Statistik, 2020. Kabupaten Teluk Bintuni dalam Angka 2020.

Hakim, Rustam, Ir. 1987. Unsur Dalam Perencanaan Arsitektur Landscape. Jakarta: Balai Pustaka

Kementerian Pekerjaan Umum, 2008. Peraturan Menteri Pekerjaan Umum Nomor : 5 tahun 2018. Tentang Pedoman Penyediaan dan Pemanfatan Ruang Terbuka Hijau di Kawasan Perkotaan, Direktorat Jendral Penataan Ruang Departemen Pekerjaan Umum, Jakarta.

Lutfi A.Salim,2020. Proyeksi Penduduk. https://www.google.com/amp/s/slideplay.info/ amp/4116294/ [20 September 2020]

Pemerintah Kabupaten Teluk Bintuni, 2012. Peraturan Daerah Kabupaten Teluk Bintuni Kabupaten Teluk Bintuni Nomor 4 Tahun 2012 Tentang Rencana Tata Ruang Wilayah Kabupaten Teluk Bintuni Tahun 2012.

Prabowo Ningsih N.H, 2018. Faktor-Faktor Yang Mempengaruhi Ketersediaan Ruang Terbuka Hijau Pada Setiap Dominasi Penggunaan Lahan (Studi Kasus Kota Surakarta). https://jurnal.uns.ac.id/region/article/view/21158. (diakses pada tanggal 1 Oktober 2020.

Radjawali, Irendra, 2004. Pemahaman terhadap pola aktivitas ekonomi untuk mengidentifikasi dan melakukan menejemen konflik pada ruang terbuka publik. Proseding makalahsimposium nasional Managing Conflicts in publik space Throught Urbab Design. Hal 83-91 


\section{Median Volume 12 Nomor 3 Bulan Oktober 2020}

Doi http://doi.org/md.v12i3.731

Undang-Undang Republik Indonesia Nomor 26 Tahun 2007 Tentang Penataan Ruang.

Wulandari, S. dkk, 2018. Implementasi kebijakan ruang terbuka hijau di kota Cirebon berdasarkan Peraturan Menteri Pekerjaan Umum Nomor 5 Tahun 2008 tentang Penyediaan dan Pemanfaatan Ruang Terbuka Hijau di awasan Perkotaan. Jurnal Ilmiah Indonesia p-ISSN: 2541-0849 e-ISSN : 2548-1398, Vol. 3, No.10 Oktober 2018. 